\title{
Connection between NAO, weather types and precipitation in León, Spain (1948-2008)
}

\author{
S. Fernández-González, ${ }^{\mathrm{a}}$ S. del Río, ${ }^{\mathrm{b}}$ A. Castro, ${ }^{\mathrm{a}}$ A. Penas, ${ }^{\mathrm{b}}$ M. Fernández-Raga, ${ }^{\mathrm{a}}$ A. I. Calvo ${ }^{\mathrm{a}, \mathrm{c}}$ \\ and R. Fraile ${ }^{\mathrm{a} *}$ \\ a Departamento de Física. IMARENAB. Universidad de León. 24071 León, Spain

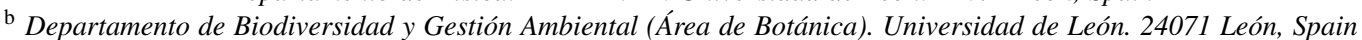 \\ ${ }^{c}$ Centre for Environmental and Marine Studies (CESAM), University of Aveiro, 3810-193 Aveiro, Portugal
}

\begin{abstract}
The variability of winter precipitation in the west of the Iberian Peninsula is strongly affected by the North Atlantic Oscillation (NAO). This study focuses on identifying the relationship that exists between precipitation registered in the city of León (in northwestern Spain), the NAO index and the associated weather type during the same period. In order to achieve this objective, the prevailing weather type has been calculated for each day in León from January 1948 to March 2009, using the objective Lamb Weather Types classification method. The most significant results appear in winter (from December to March). During these months an increase has been observed in the frequency of 'anticyclonic' weather type (A) (very dry), and a decrease in the 'cyclonic' (C), 'south-westerly' (SW) and 'westerly' (W) types (the three rainiest weather types). The positive trend in the NAO index could be the main cause of the decrease in the frequency of the three rainiest weather types $(\mathrm{C}, \mathrm{SW}$ and $\mathrm{W})$ and therefore, responsible for the relevant decline in winter precipitation observed in the city of León. The high correlation coefficients between the NAO index, the frequency of the three rainiest weather types and winter precipitation suggests an interesting method to forecast rainfall. Using a binary logistic regression model, a downscaling model for daily precipitation has been obtained based on the weather types and the NAO index. The daily results obtained for the winter months are good $($ TSS $=0.64)$ bearing in mind that only sea level pressure data were used in the logistic model. Copyright (c) 2011 Royal Meteorological Society
\end{abstract}

KEY WORDS logistic regression; rainfall; weather types; Spain; North Atlantic Oscillation

Received 5 December 2010; Revised 1 August 2011; Accepted 18 September 2011

\section{Introduction}

The rainfall regime in the Iberian Peninsula is highly irregular, on both the spatial and the temporal scale (Esteban-Parra et al., 1998). As a result of the orography and the oceanic origin of precipitation, synoptic disturbances contribute towards the spatial variability of the precipitation (Trigo et al., 2004). The interannual variability of precipitation that occurs during the winter, and to a lesser degree during the autumn, may be explained by changes in large-scale atmospheric circulation modes, especially for the western sector of the Iberian Peninsula (Rodríguez-Puebla et al., 1998; Trigo and Palutikof, 2001).

Many authors have identified a trend towards a drier climate in Spanish Iberia over the last few decades (Esteban-Parra et al., 1998; Hulme and Sheard, 1999; Mossman, 2002; Paredes et al., 2006; IPCC, 2007). The decrease in winter precipitation in different areas of the Iberian Peninsula has also been the subject of other studies (López-Bustins et al., 2008; Rodrigo and Trigo,

\footnotetext{
* Correspondence to: R. Fraile, Departamento de Física, Facultad de CC Biológicas y Ambientales, 24071 León, Spain.

E-mail: roberto.fraile@unileon.es
}

2007). Recently, del Río et al. (2011) carried out a study on precipitation trends for the whole of Spain between 1961 and 2006, and found negative trends in more than $75 \%$ of the weather stations analysed. This decrease is significant in $18 \%$ of mainland Spain.

The phenomenon of the North Atlantic Oscillation (NAO) is one of the most important factors in the climate of the Northern Hemisphere, as it transports heat from one part of the world to the other (van Loon and Rogers, 1978; Hurrell, 1996). Over the last few decades, especially since the 1980s (Hurrell and van Loon, 1997), a major increase in the annual NAO index has been observed, especially between the months of December and March. The main consequences of this increase in the NAO index are regional changes in the precipitation patterns (Hurrell, 1995; Dai et al., 1997). Hurrell and van Loon (1997) showed that a high NAO index during the winter correspond to higher than normal precipitation in western Scandinavia, Denmark and northern parts of Ireland and Great Britain. In contrast, a high NAO index leads to drier than normal conditions in the Iberian Peninsula and the western Balkans. As a result of the increase observed in the NAO index, there has been a drop in winter precipitation in southwestern Europe. This trend is not easy to see in the case of Spain 
due to the complex spatial and temporal distribution of the precipitation, as the vast majority of the country is affected by a Mediterranean climate.

The NAO index is the most important parameter used to model the winter rainfall regime in the Iberian Peninsula (Rodó et al., 1997; Trigo and Palutikof, 2001). Good correlations were obtained between winter precipitation and the NAO index in different territories of Spain (Zorita et al., 1992; Muñoz-Díaz and Rodrigo, 2004; García et al., 2005; Lorenzo and Taboada, 2005; Rodrigo and Trigo, 2007; Queralt et al., 2009), and an attempt has been made to predict precipitation using the values of the NAO index (Castro et al., 2011). In the western Mediterranean area, the NAO may explain up to $50 \%$ of the variability of precipitation during the spring (Martín et al., 2004).

The modes of variability and weather types are two approaches for dealing with atmospheric circulation. Initially, weather types were classified according to the dominant synoptic situation on a given day. This involved establishing a series of specific isobaric configurations, and all the days when isobars had this configuration were assigned to the same type. This meant that the circulation was classified based on sea level pressure. This is actually a circulation-to-environment approach. Today, there is a tendency to use weather types classified according to objective criteria, such as those developed by Spellman (2000), which have the advantage of being observer-independent. The models used for the automatic classification of the synoptic situation were initially developed for the British Isles (Jones et al., 1993). Huth et al. (2008) have offered an excellent review about catalogues of circulation-types classifications.

In recent years, several authors have published different automatic classification models for the Iberian Peninsula, most of which are connected to a specific climatic application. Goodess and Palutikof (1998) adapted one of these methods for the southeast of Spain. In a later study, Goodess and Jones (2002), identifying the relationships between large-scale atmospheric circulation and daily precipitation in different parts of the Iberian Peninsula, demonstrated the relationship between an increased frequency of the anticyclonic weather type and an increase in the NAO index. They also found positive correlations between the frequency of the cyclonic weather type and precipitation in many parts of the Iberian Peninsula. Corte-Real et al. (1999) established four daily atmospheric circulation patterns associated with precipitation in Portugal: 'blocking-like', 'summer dry', 'winter dry' and 'rainy'.

Classifications of this kind have also been used to obtain climate change scenarios (Goodess and Palutikof, 1998), even associating the electrical activity of storms with atmospheric circulation (Tomás et al., 2004). Some authors have gone even further and proposed methods for predicting precipitation, based on the relationships between atmospheric circulation and precipitation (Heyen et al., 1996; Zorita and von Storch, 1997). Queralt et al. (2009) claim that the NAO index and weather types have a significant influence on rainfall regimes, with the effects varying widely depending on the area of the Iberian Peninsula selected.

Recently, these automatic classification methods have been used to study variability and changes in the characteristics of precipitation (Paredes et al., 2006). Lorenzo et al. (2008) modified the method developed by Trigo and DaCamara (2000) to adapt it to the Spanish region of Galicia.

Several authors have focused their studies on the winter months (Rodríguez-Puebla et al., 2001; Sáenz et al., 2001). Zorita et al. (1992) confirmed the relationship between NAO and winter precipitation in the Iberian Peninsula. It also focused on the winter months, as this is when the most significant results are obtained.

In this study, a logistic regression model has been used to define a nowcast on whether precipitation will be registered or not on a given day in our study area, based on the parameters used to obtain weather types and the NAO index. This type of model has already been used to study the environment. For example, Jomeli et al. (2007) make use of a logistic regression model to analyse the probability of avalanches occurring, based on the precipitation registered on the day before the avalanche, the precipitation that has fallen on the day of the avalanche and on the previous day, or only on the day of the avalanche.

Logistic regression models have also been used for the short-term forecasting of storms and hailstorms (MarcosMenéndez, 2001). This study offers a forecast in binary terms (yes/no) for storm phenomena. Angus et al. (1988) and Billet et al. (1997) both used this type of model for the short-term forecasting of storm events. This model has also been used to study the probability of precipitation (Crosby et al., 1995), and, more recently, the visibility factor at airports (Hiliker and Fritsch, 1999).

The main aims of this article are to:

1. Obtain an objective classification of weather types in León, Spain, from January 1948 to March 2009, identifying significant variations of their frequency on a monthly, seasonal and annual scale.

2. Analyse the trends observed from 1948 to 2009 in winter precipitation in the city of León.

3. Compute the relative contribution of each weather type and the NAO to precipitation in León, especially during the winter months.

4. Derive a downscaling system for daily rainfall based on a logistic regression model, using various parameters elaborated from sea level pressure data.

This article is organized as follows: Section 2 defines the study area; Section 3 details the data and methodology used; Section 4 details the different results obtained in this article, together with the discussion. Finally, Section 5 offers a summary of the conclusions, followed by the acknowledgements and bibliographic references. 


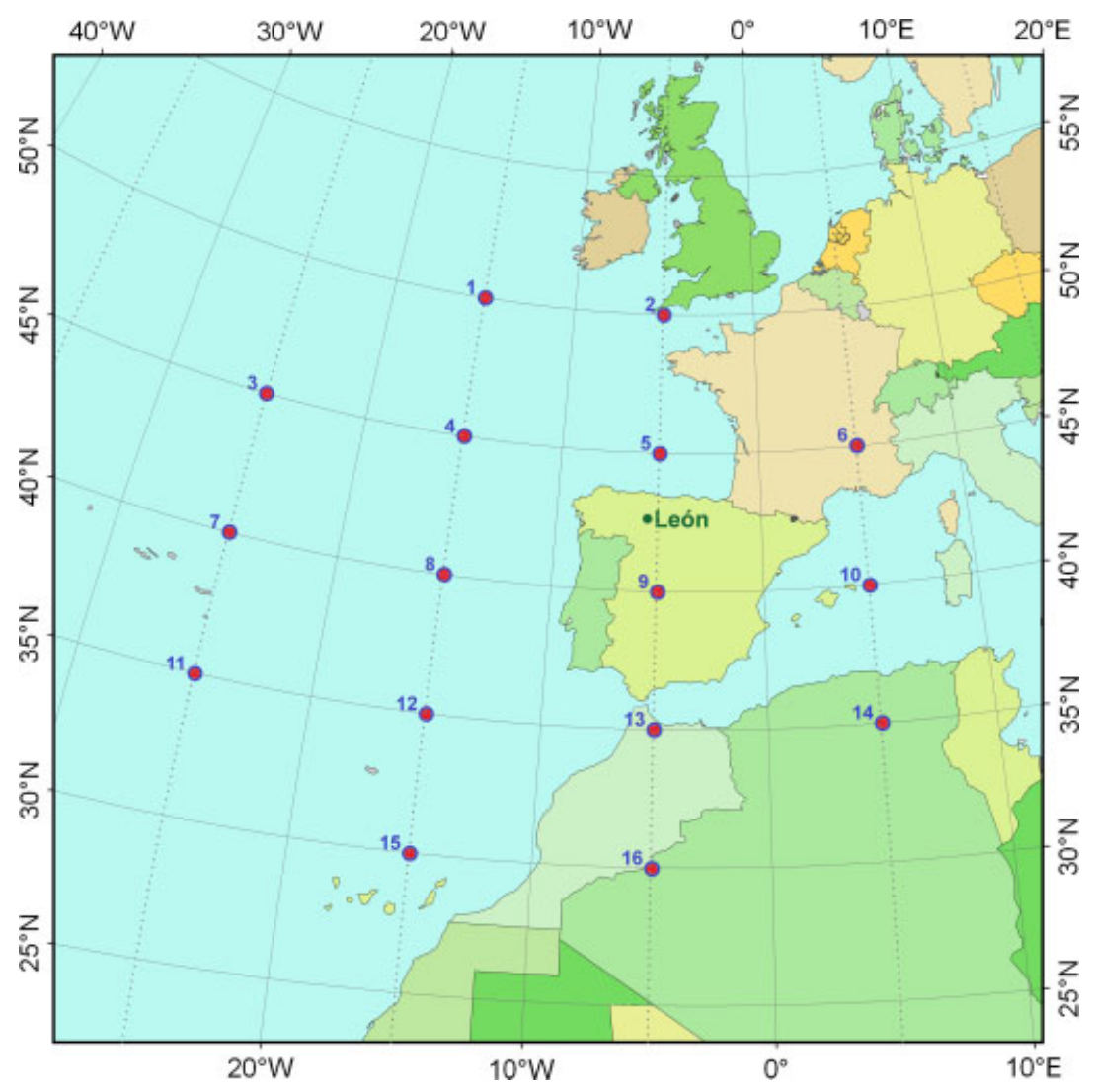

Figure 1. Location of León. Grid formed by 16 dots from which the values of sea level pressure are obtained. This figure is available in colour online at wileyonlinelibrary.com/journal/joc

\section{Study area}

The city of León is situated in the northwest of the Iberian Peninsula (Figure 1), at $42^{\circ} 36^{\prime} \mathrm{N}, 5^{\circ} 35^{\prime} \mathrm{W}$, on a fluvial terrace at a point where the rivers Bernesga and Torío converge, at an altitude of 838 meters above sea level. The city is in the centre of the province of León, in the northwest of the Duero Basin, flanked to the north by the Cantabrian Range and to the west by the Mountains of León, which isolate the city from the oceanic influence.

The precipitation in northwestern Iberia is characterized by a seasonal behaviour, mainly influenced by the Atlantic Ocean but also by the Mediterranean Sea. During the summer, the dominant winds from the west are displaced towards the north, allowing the Azores High to extend its influence over the Iberian Peninsula. In autumn, spring and winter, precipitation is mainly related to baroclinic disturbances coming from the Atlantic (GarcíaHerrera et al., 2005), while in summer, the scarce precipitation has a dominant convective and, therefore, more local character (Serrano et al., 1999; Muñoz-Díaz and Rodrigo, 2006). León has a Mediterranean climate with regard to precipitation regime (rainy springs and autumns, and dry summers), and a continental climate type with regard to its temperature regime (with wide temperature ranges, even on the same day, and with frequent frosts). The north of Spain is warm in the summer due to the Mediterranean influence (Andrés et al., 2000).
According to our database, from January 1948 to March 2009, the mean annual precipitation in the city of León is $545.7 \mathrm{~mm}$, distributed in a rainy season in the months between October and May, two months with low precipitation - June and September - and two months of summer drought - July and August. The term 'summer drought' is used from a bioclimatological perspective (Rivas-Martínez, 2007), if the precipitation is less than twice the temperature during at least two consecutive months in the summer. These factors give León a Mediterranean climate.

\section{Methodology}

\subsection{Datasets}

We were provided with daily and monthly precipitation data by the State Meteorological Agency (Agencia Estatal de Meteorología, AEMET). We have data on monthly precipitation from January 1948 to December 1993 (representing a sample of 552 datasets on monthly precipitation), and daily precipitation from January 1994 until March 2009 (representing 5569 datasets on daily precipitation). Although at first the study was only intended to deal with data from between 1948 and 2008, it was extended up to March 2009 in order to complete this last winter. All the precipitation data are taken from the weather station at the airport of La Virgen del Camino, at a distance of six kilometres from the city of León. 
This station lies on flat, open terrain, and is not affected by the recent urban expansion of the city. This is a complete dataset, i.e. no intervention has been required to reconstruct or complete it.

With regard to the daily sea level pressure data, required to calculate the weather type, these were obtained from the National Center for Atmospheric Research (NCAR). Daily sea level pressure data are available for 16 grid points, from January 1948 to March 2009 (weather type data sample $=22373$ days). In order to calculate the values of the NAO index, data were also obtained from the same source. A specific daily NAO index was created, by subtracting the value of point $65^{\circ}$ North, $22.5^{\circ}$ West (approximately $1^{\circ}$ to the south and $1^{\circ}$ to the west of Reykjavik) from the pressure value for point $37.5^{\circ}$ North, $5^{\circ}$ West (approximately $1^{\circ}$ to the north and $0.2^{\circ}$ to the east of Gibraltar), as the index obtained from these points is better adapted to our latitudes. It was found that on a monthly scale, the values of the NAO index calculated this way coincide with those calculated from the exact definition of the NAO index (Jones et al., 1997).

\subsection{Weather types}

In order to achieve our objective, we applied the procedure described by Lamb (1972), further developed at a later stage by Jenkinson and Collison (1977) and Jones et al. (1993), and used to objectively define weather types in the British Isles, from indices based on the direction and vorticity of the geostrophic wind. This method was subsequently adapted by Trigo and DaCamara (2000) to study the rainfall regime in Portugal.

The classification of weather types was carried out objectively and grouped weather types according to 6 variables, calculated from daily sea level pressure at 16 points around the Iberian Peninsula (Figure 1). It was actually the same grid used by Trigo and DaCamara (2000). The six parameters used are: southerly flow $(S F)$, westerly flow $(W F)$, total flow $(F)$, southerly shear vorticity $(Z S)$, westerly shear vorticity $(Z W)$ and total shear vorticity $(Z)$. For a detailed explanation on the calculation of these parameters and on the definition of the different types of circulation, see Trigo and DaCamara (2000). Paredes et al. (2006) also offer a good synthesis of this weather type classification scheme.

These values were calculated on a daily basis from January 1948 to March 2009. The method classifies the synoptic situation for each day into one of the 26 possible types of atmospheric circulation (Table I).

In our study, we have not regrouped the hybrid types within the non-directional types, contrary to other authors (Trigo and DaCamara, 2000; Lorenzo et al., 2008), as the results obtained for the probability of precipitation and average daily rainfall were very different in the nondirectional and the hybrid types; they were not considered comparable and, therefore, the 26 original weather types were maintained.
Table I. Classification of the 26 existing weather types.

\begin{tabular}{lcll}
\hline \multicolumn{3}{c}{ WEATHER TYPES (26) } \\
\hline Directional types & Non-directional types & Hybrid types \\
\hline Northerly (N) & Anticyclonic (A) & AN & CN \\
Southerly (S) & Cyclonic (C) & ANW & CNW \\
Easterly (E) & & AW & CW \\
Westerly (W) & & ASW & CSW \\
Northwesterly (NW) & AS & CS \\
Southwesterly (SW) & ASE & CSE \\
Southeasterly (SE) & & AE & CE \\
Northeasterly (NE) & & ANE & CNE \\
\hline
\end{tabular}

\subsection{Trend analysis}

Linear and non-parametric models can be applied to carry out the trend analysis, both for the frequency of the weather types, monthly, seasonal and annual precipitation and the NAO index. In this study, linear correlation and the Mann-Kendall test have been used for analysing the trends. These methods have been described by Sneyers (1990) and del Río et al. (2005).

On describing the Mann-Kendall test, Sneyers (1990) indicates that both this method and parametric tests, such as the normal linear regression, are highly efficient tests and have the same asymptotic efficacy. The main difference is that the Mann-Kendall test also makes it possible to calculate the start of the trend. Nevertheless, in this study, the linear model has also been used to identify and characterize the trends.

Positive (negative) values indicate an upward (downward) trend in the frequency of the weather types or in the precipitation. Throughout the whole article, values of the trends for a confidence level of $95 \%(\alpha=0.05)$ will be considered significant. The existence of a statistically significant trend will be evaluated using the value of the linear correlation coefficient $r$ and the value $u(t)$ of the Mann-Kendall test (the trend is statistically significant if $|u(t)|>1.96)$.

\subsection{Logistic regression model}

The objective of this model is to provide a nowcast in binary terms (yes/no) of the precipitation expected on a given day in León. The analysis has been carried out with daily pressure and precipitation data from between January 1994 and March 2009. The sample period consists of a total of 5569 days. The logistic regression model attempts to relate a response variable (in our case if it rained or not) in the best possible way with a series of explanatory variables, which in our case are $S F, W F, F, Z S, Z W$ and the NAO index (the $2 F$ and $Z$ parameters have been excluded because they do not offer any additional information to $F, Z S$ and $Z W$ ). The response variable is discrete in nature, as it can only have one of two values (yes/no), i.e. it is binary or dichotomic. We will therefore codify our response variable with the two possible values: 1 and 0 . We will use value 1 for the 
days on which precipitation was recorded, and use value 0 for the rest.

We will now turn to the mathematical description of the model, based on Kleinbaum (1992).

Firstly, the function we will refer to as the logistic function is defined as follows:

$$
f(z)=\frac{1}{1+e^{-z}}
$$

The range values of the function are between 0 and 1 , namely:

$$
0 \leq f(z) \leq 1
$$

The values of the explanatory variables (which are meteorological magnitudes) from a given day have been included in the YES group or in the NO group after classifying the risk situations. The explanatory variables are combined forming the variable $z$. This variable is the base to compute the function $f(z)$, which may have values between 0 and 1, making it possible to interpret the values of the logistic function as a probability function. As a result, the value of $f(z)$ may be interpreted as the risk of a certain event occurring, with this risk increasing the closer the value of $f(z)$ approaches to 1 .

The value of $z$ is a linear combination of the explanatory variables, whereby

$$
z=\alpha+\left(\beta_{1} X_{1}+\beta_{2} X_{2}+\ldots+\beta_{n} X_{n}\right)
$$

where $X_{i}$ are each of the meteorological magnitudes used as explanatory variables, $\alpha$ is the independent term that provides the resulting model, and $\beta_{i}$ the coefficients of each explanatory variable, also obtained by the model, according to the data introduced that consists of the explanatory variables and the response variable, measured for the total number of days included in the sample. In this case, $n=7$. Having estimated these 7 coefficients and the independent term, we arrive at the final expression

$$
P(x)=\frac{1}{1+e^{-\left(\alpha+\beta_{1} X_{1}+\beta_{2} X_{2}+\ldots+\beta_{n} X_{n}\right)}}
$$

where $P(x)$ is the probability of rain on a certain day.

This model has been evaluated using contingency tables (Table II), also assessing other parameters of interest, such as the False Alarm Ratio (FAR), which represents the days on which precipitation was not registered, despite the fact that it had been predicted by the model, and the Frequency Of Misses (FOM), which represents the days on which precipitation was registered, but the model had not predicted rain (Table II). Of course, the lower these two values, the more reliable the model.

However, in order to establish the goodness of a dichotomous prediction, it is not enough to know the number of mistakes that can distort the result to some extent, as when the $z$ and $y$ of the matrix provide an incorrect perspective of the forecast. In other words, the FAR and FOM indices are not sufficient: it is also
Table II. Contingency table for the logistic regression model, and forecast goodness indices.

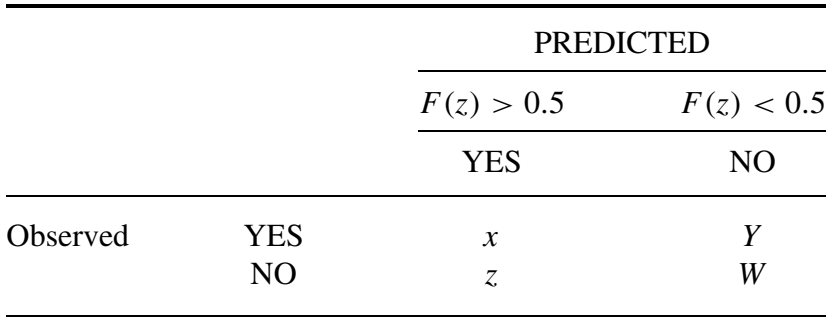

$$
\begin{aligned}
& F A R=\frac{z}{x+y} \\
& F O M=\frac{y+y}{x+y} \\
& T S S=\frac{x w-y z}{(x+y)(z+w)} \\
& H S S=\frac{2(x w-y z)}{(x+z)(z+w)+(x+y)(y+w)} \\
& K S S=\frac{x w-y z}{(x+z)(y+w)} .
\end{aligned}
$$

necessary to jointly analyse the four variables shown in the contingency table (Table II). The forecast goodness indices, which are usual in predictive models (Doswell et al., 1990; Jacovides and Yonetani, 1990), are based on the calculation of skill scores to validate the model. For example, Sánchez et al. (1998) used this type of discriminatory analysis in order to find the relationship between a categorical variable and a series of interrelated variables in their study on the probability of storms in León. In this study, three scores for validating the prediction of thunderstorms were calculated (Table II): the True Skill Statistic (TSS), described by Wilks (1995), occasionally referred to as Q by Dobryshman (1972); the Heidke Skill Score (HSS), defined by Panofsky and Brier (1958), which is equivalent to the TSS when the values of $Y$ and $Z$ are the same, and Kuipers Skill Score (KSS), proposed by Wilks (1995), which obtains more realistic results in the forecasting of unusual events, such as storms. Manzato (2005) proposed a simple approximation for some of these indices, such as HSS and KSS, known as the odds ratio. The odds ratio is parameterized as a function of the Probability of Detection (POD), and leads to a parameterisation of all the theoretical Relative Operating Characteristic (ROC) curves.

The details of the skill scores have been described by Jolliffe and Stephenson (2003). Their main features are: the definition of the TSS is the probability of a predicted event occurring, minus the probability of an event not occurring in an unexpected way; the Heidke Skill Score (HSS) provides a guarantee to correct all the forecasts that are not exclusively due to chance (Huntrieser et al., 1997); the KSS index is better adapted to rare events, such as storms or hailstorms.

Obviously, the higher these three values, the more efficient the model obtained. This leads us to consider that the probability of rain falling on a given day may perhaps not be the best criterion; establishing 0.5 as the probability threshold discriminating between rainfall and no rainfall may not lead to the best values of the skill scores. So, we did the opposite, identifying the best 
threshold value of the probability, in order to maximize the forecast goodness indices.

\section{Results and discussion}

\subsection{Classification of weather types}

As mentioned above, a classification of daily weather types was set up from January 1948 to March 2009, using daily sea level pressure data from the National Center for Atmospheric Research (NCAR). This classification can be of great use for describing the climate of León. Table III summarizes this classification showing each weather type with its average annual frequency, trend, probability of rainfall (based on the percentage of days with rainfall observed with each weather type) and the precipitation measured on days with rainfall.

The average yearly frequency and the trend were calculated using daily pressure data from January 1948 to March 2009, while the probability of rainfall and average precipitation for days with rainfall have been calculated using data from January 1994 to March 2009.

The table shows that the anticyclonic weather type is clearly dominant in terms of frequency, with an average of more than 81 days per year. This coincides with the result obtained by Lorenzo et al. (2008), in their study on the relationship between weather types and precipitation in Galicia, Spain. It should also be noted that this frequency is increasing over the period considered, as revealed by the trend. Table III clearly and concisely shows the relative importance of each weather type, as it not only depicts the average annual frequency of each weather type, but also details the probability of rainfall and the expected precipitation.

Here, the positive trends of the weather types A, ASE, CSE, CN, SE, E and SW stand out. With the exception of $\mathrm{CN}$ and $\mathrm{SW}$ types, the rest are very dry weather types. However, we may see negative trends for the weather types ANE, AN, CW, NE and W. The negative trends of the weather types $\mathrm{CW}$ and $\mathrm{W}$, together with the positive trends of CSE, ASE, SE and E reflect a decrease in the frequency of days with dominant winds from the west (during which there is a high probability of rainfall), and an increase in the days with predominant winds from the east and southeast (very dry).

The highest daily precipitation was found in the CSW weather type, with average precipitation on days with rainfall of more than $9 \mathrm{~mm}$. Rainfall averages of more than $7 \mathrm{~mm}$ were also found for the weather types SW, $\mathrm{CW}$ and $\mathrm{CNW}$, and more than $6 \mathrm{~mm}$ with $\mathrm{C}, \mathrm{CS}, \mathrm{CE}$ and $\mathrm{W}$. In contrast, with the weather types A, ASE, AS, AE, ANE, AN and ANW the expected rainfall is virtually zero, as the probability of rainfall is less than $10 \%$, or the average precipitation on days with rainfall is less than $2 \mathrm{~mm}$.

\subsection{Trends in weather type frequencies}

The analysis included the trends for the main weather types from 1948 to 2008. We selected the 'anticyclonic'
Table III. Objective classification of the frequency of different weather types in León (January 1948-March 2009). The trend is shown by the correlation coefficient (significant values for $\alpha=0.05$ are marked with ${ }^{*}$ ). The data on the probability of rainfall and daily average rainfall are based on readings made between January 1994 and March 2009.

\begin{tabular}{|c|c|c|c|c|}
\hline \multirow[b]{2}{*}{$\begin{array}{l}\text { Weather } \\
\text { types }\end{array}$} & \multicolumn{2}{|c|}{$1948-2009$} & \multicolumn{2}{|c|}{ 1994-2009 } \\
\hline & $\begin{array}{l}\text { Annual average } \\
\text { frequency } \\
\text { (days) }\end{array}$ & Trend & $\begin{array}{l}\text { Probability } \\
\text { of rainfall } \\
(\%)\end{array}$ & $\begin{array}{l}\text { Daily } \\
\text { Average } \\
\text { rainfall } \\
(\mathrm{mm})\end{array}$ \\
\hline A & 81.4 & 0.16 & 13.0 & 1.6 \\
\hline AS & 2.3 & 0.00 & 2.9 & 4.5 \\
\hline ASE & 2.6 & 0.17 & 2.3 & 0.3 \\
\hline $\mathrm{AE}$ & 5.7 & 0.01 & 4.7 & 0.8 \\
\hline ANE & 15.9 & -0.24 & 4.1 & 1.7 \\
\hline $\mathrm{AN}$ & 15.8 & $-0.30^{*}$ & 15.1 & 1.7 \\
\hline ANW & 12.6 & 0.02 & 38.7 & 1.7 \\
\hline AW & 12.1 & 0.02 & 62.2 & 2.7 \\
\hline ASW & 6.5 & 0.09 & 43.0 & 2.5 \\
\hline $\mathrm{C}$ & 22.4 & 0.06 & 56.5 & 7.0 \\
\hline CS & 2.0 & 0.06 & 51.6 & 6.0 \\
\hline CSE & 2.3 & 0.13 & 26.9 & 1.2 \\
\hline $\mathrm{CE}$ & 3.6 & -0.03 & 19.0 & 6.5 \\
\hline $\mathrm{CNE}$ & 5.4 & -0.01 & 37.0 & 4.2 \\
\hline $\mathrm{CN}$ & 3.7 & 0.14 & 62.2 & 3.5 \\
\hline CNW & 2.2 & 0.06 & 89.3 & 7.1 \\
\hline $\mathrm{CW}$ & 2.7 & -0.10 & 80.6 & 7.6 \\
\hline CSW & 2.8 & 0.08 & 89.1 & 9.0 \\
\hline S & 6.1 & -0.09 & 34.1 & 2.2 \\
\hline SE & 7.3 & 0.11 & 6.7 & 3.0 \\
\hline $\mathrm{E}$ & 18.7 & 0.17 & 6.6 & 2.3 \\
\hline $\mathrm{NE}$ & 45.2 & -0.20 & 11.0 & 3.4 \\
\hline $\mathrm{N}$ & 31.3 & 0.00 & 34.2 & 3.9 \\
\hline NW & 17.3 & -0.09 & 57.7 & 2.8 \\
\hline W & 21.8 & -0.13 & 81.7 & 6.0 \\
\hline SW & 15.8 & 0.11 & 70.5 & 7.4 \\
\hline
\end{tabular}

(A), 'cyclonic' (C), 'westerly' (W) and 'southwesterly' (SW) weather types, as they are considered the 4 most important weather types when defining the climate of León: The first of these weather types is the most frequent and, as will be seen in Section 4.3, the remaining three are the main causes of the precipitation recorded in León. The aim of this analysis was to identify the causes of the trends, and the possible consequences.

The 'anticyclonic' weather type (A) is very important, as it has a clearly prevailing influence on the climate in León. This synoptic situation appears in León when the Azores High is strengthened and shifted slightly to the east of the Azores, with its front edge entering the Iberian Peninsula. In winter, it also appears when the Peninsula behaves as a source region of a very cold air mass, which acts as a barrier against oceanic fronts and low-pressure zones, leading to very stable weather. Another situation that may occur is when the European anticyclone encompasses the Iberian Peninsula. This weather type is more frequent in the winter months 


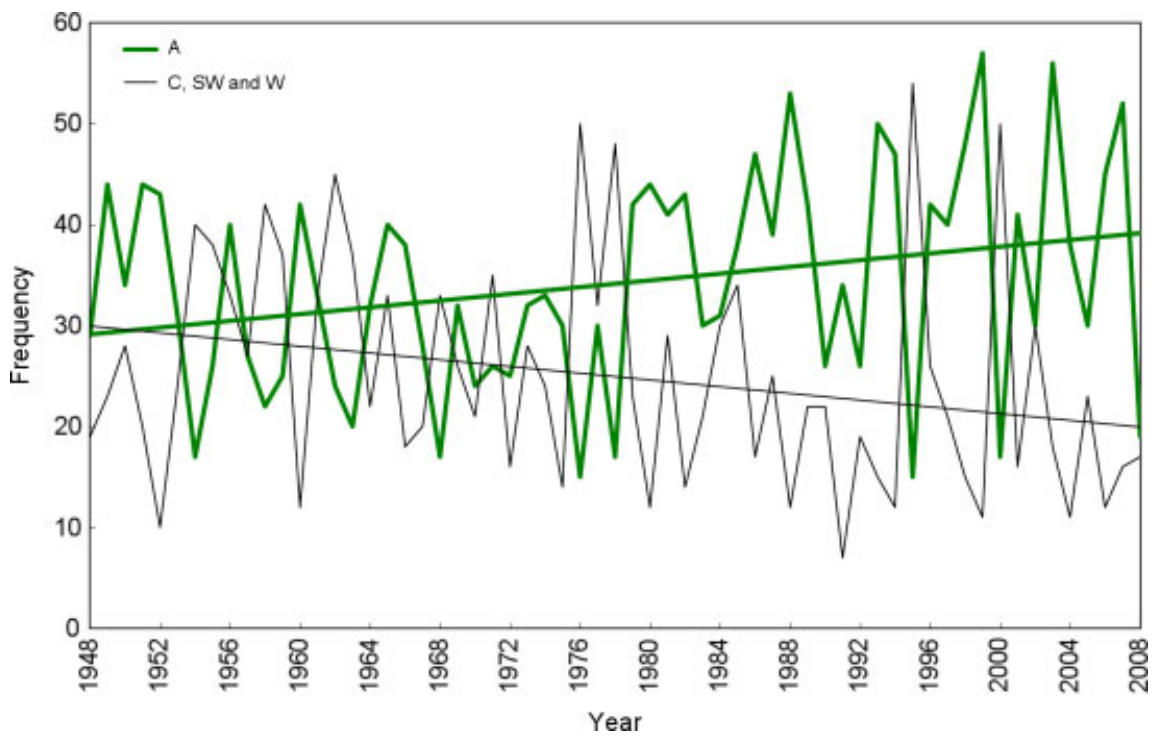

Figure 2. Frequency of selected weather types between the months of December and March (1948-2008). The thick lines represent the 'anticyclonic' (A) weather type and its trend, and the fine lines represent the 'cyclonic' (C), 'westerly' (W) and 'southwesterly' (SW) weather types and their trends. This figure is available in colour online at wileyonlinelibrary.com/journal/joc

(with a frequency of $35 \%$ ), with a very low probability of precipitation during these days, of around $13 \%$. It leads to very stable weather conditions, causing radiation fog and severe frost in winter.

The frequency of this synoptic situation has increased significantly over the last few decades, especially in winter (Figure 2), and it is now one of the causes for the decrease in precipitation during the months December to March. In all likelihood, the increase of the NAO index over the last few decades has led to the increase in the frequency of the anticyclonic weather type. This is in agreement with other studies, for example: Pozo-Vázquez et al. (2004) have detected an association between NAO and solar radiation due to cloudless (anticyclonic) weather; del Río et al. (2005) found that a high NAO index causes frequent anticyclones and dry weather over wide areas of southern Europe; and Paredes et al. (2006) observed that low-pressure systems have become less frequent during the past four decades, when positive NAO phases have been detected.

In contrast, a significant decrease has been noted in the total frequencies of the three weather types responsible for most of the precipitation, as discussed in Section 4.3. This decrease is most prominent in the winter months (Figure 2). The three synoptic situations are 'cyclonic' (C), 'westerly' (W) and 'southwesterly' (SW) and occur when the Azores High is weakened, allowing the Icelandic Low to shift to lower latitudes facilitating or allowing the arrival of associated fronts to the Iberian Peninsula.

If we compare both curves in Figure 2, we can see that the years with a high 'anticyclonic' frequency have low values for the frequency of the three rainiest weather types, and vice versa. On quantifying the relationship between both frequencies, a significant correlation coefficient has been found. This leads us to believe that the frequency of these weather types is controlled by another variable, probably the NAO index.

\subsection{Weather types and precipitation}

With the aim of studying the relationship between weather types and precipitation in León, these data were analysed on a daily basis in order to obtain a classification of the characteristics of the precipitation in the study zone that could help us understand the local climatology in greater detail. The amount of rainfall provided daily by each weather type between 1994 and 2008 was calculated to estimate the relative importance of each weather type. The result was that the 'cyclonic' (C), 'westerly' (W) and 'south-westerly' (SW) types provide more precipitation than the other 23 types taken together.

Figure 3 shows the clear predominance of the 'anticyclonic' weather type (A) with regard to the rest. This weather type represents nearly $23 \%$ of the days. The next most frequent type is 'northeasterly' (NE), also a very dry weather type. However, the sum of the frequencies of the three rainiest weather types, 'cyclonic' (C), 'westerly' (W) and 'southwesterly' (SW), only represent $17.3 \%$ of the total. Similar results were found by Lorenzo et al. (2008)

Figure 3 also shows that there are 5 weather types with a probability of rainfall of more than $70 \%$ : these are CNW, CW, CSW, W and SW. Another 4 weather types are shown with a probability of between 50 and 70\%: AW, C, CN and NW. At the other end of the scale, we find 9 weather types with less than $15 \%$ of days with precipitation: A, AS, ASE, AE, ANE, AN, SE, E and NE, most of which are characterized by having anticyclonic features and/or easterly circulation. This figure shows that most of the precipitation comes from weather types associated with westerly winds from the Atlantic Ocean (García-Herrera et al., 2005). On the other hand, on days 


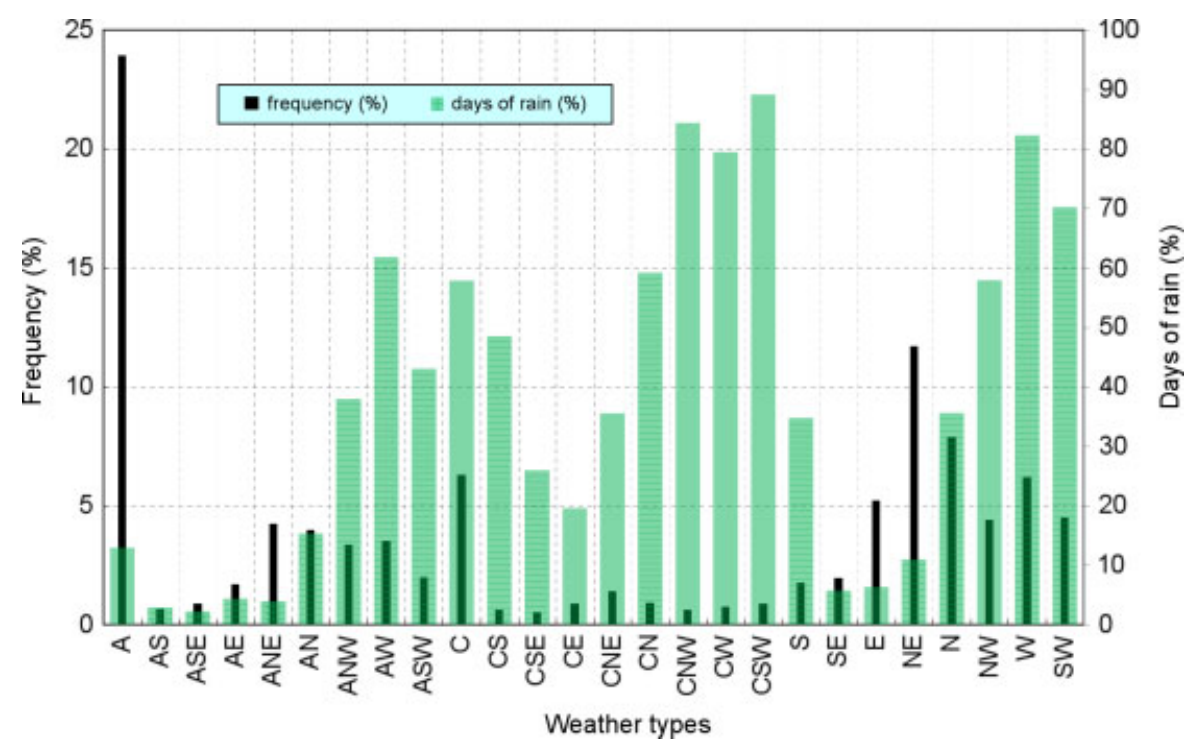

Figure 3. Frequency and percentage of days with rainfall for each weather type between 1994 and 2008. This figure is available in colour online at wileyonlinelibrary.com/journal/joc

with weather types accompanied by easterly winds (when the air reaching León is dry), practically no precipitation is recorded.

As we can see in Figure 4, three weather types provide most of the yearly precipitation, exactly $55.4 \%$. These weather types are 'cyclonic' (C), 'westerly' (W) and 'southwesterly' (SW). Similar results were obtained for Galicia, Spain by Lorenzo et al. (2008). The weather types N, NW and CSW also usually lead to precipitation, although their relative importance when analysing the local climate of León is minor, as they only appear with a very limited frequency.

By analysing only the winter months (from December to March), the percentage of rainfall contributed by the 3 rainiest weather types (C, SW and $\mathrm{W}$ ) rises to $64 \%$ (Figure 4). In particular, an increase may be seen in the precipitation recorded on days with the SW weather type. These results coincide with those obtained by Trigo and DaCamara (2000), who indicated in their study on the rainfall regime in Portugal that the three rainiest weather types are 'cyclonic' (C), 'westerly' (W) and 'south-westerly' (SW) (the same three that were found for León). The authors state that although they only appear on $32 \%$ of the days during the winter months in Portugal, they account for $62 \%$ of all winter precipitation, a result that is very similar to the figure of $64 \%$ for winter precipitation recorded in León.

\subsection{Evolution of the precipitation}

The analysis of the evolution of annual precipitation using linear and non parametric models showed a slight decrease in the period between January 1948 and December 2008. This decrease is indicated by a correlation coefficient of -0.14 (which does not represent a significant trend for $\alpha=0.05)$. As an overall evaluation, it may be said that since 1948, annual precipitation has decreased by a yearly average of slightly more than
$1 \mathrm{~mm}$ per year. These values coincide with the trends observed and predicted by González-Rouco et al. (2000), who indicated that decreases of up to $10 \mathrm{~mm}$ per decade could occur in some central and southern parts of the Iberian Peninsula. Several studies on this upward trend in annual precipitation in Spain have already been carried out (Esteban-Parra et al., 1998; Mossmann, 2002; Paredes et al., 2006; IPCC, 2007), with similar results.

If instead of a linear model, we apply a second order polynomial model to the annual evolution of precipitation, a convex curve is obtained in the period from 1948 to 2008, which is statistically significant ( $\alpha=$ 0.05) and has a maximum around 1969 (Figure 5). Before this maximum (between 1948 and 1969) the volume of rainfall was rising at a rate of $3 \mathrm{~mm}$ per year. Since then, annual precipitation has decreased by an average of $2.4 \mathrm{~mm}$ per year, representing a more dramatic decrease than that indicated in the literature mentioned above.

A more exhaustive analysis of annual precipitation was carried out, comparing the following two periods: 1948-1969 and 1970-2008, separated by a change in the trend, as mentioned above. The monthly evolution of precipitation is shown in Figure 6. The comparison of the two periods revealed significant decreases in precipitation in the months of February, March and November. In contrast, slight increases may be seen in the months of May, July, August and October. In the latter period (1970-2008), we see that precipitation has tended towards being distributed in two maximums and two minimums throughout the year. The first maximum corresponds to the months from October to January, and the second to the months of April and May, while the minimums correspond to the months of February and March, and from June to September.

The decrease in precipitation in the month of March in these two periods is the most dramatic one. We see a decrease of $46 \%$, from an average of $60 \mathrm{~mm}$ in 


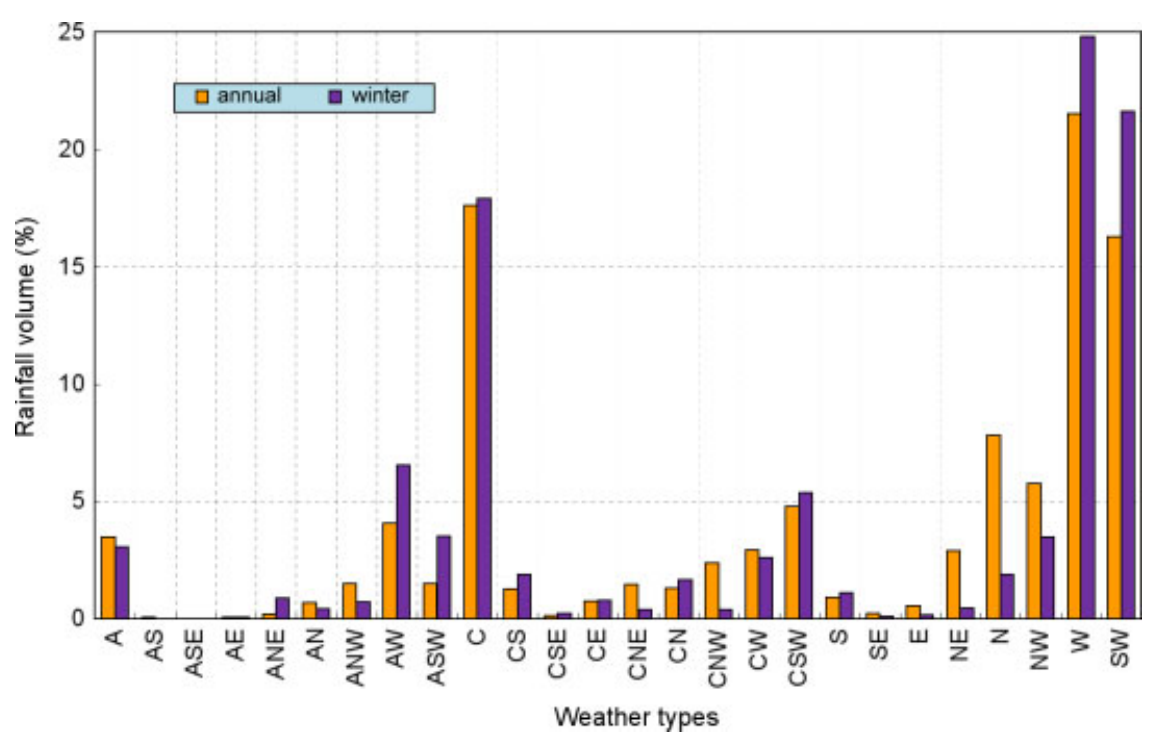

Figure 4. Percentage of annual and winter (December-March) precipitation for each weather type between 1994 and 2008. This figure is available in colour online at wileyonlinelibrary.com/journal/joc

the months of March between 1948-1969, to $33 \mathrm{~mm}$ between 1970 and 2008. Also noteworthy is the decrease in precipitation in the month of November, from an average of more than $70 \mathrm{~mm}$ to barely $54 \mathrm{~mm}$, a decrease of 24\%. Del Río et al. (2011) obtained similar results in most of Spain.

Considering the overall period (1948-2008), the highest monthly decrease in precipitation also occurs in the month of March, with a statistically significant negative trend $(r=-0.27)$. The decrease seen in this month has been confirmed by numerous studies (Trigo and $\mathrm{DaCa}-$ mara, 2000; Mossmann, 2002; del Río et al., 2005). Statistically significant negative trends are found in central parts of Spain (Mossmann et al., 2004). Paredes et al. (2006) relate this to the increase in the NAO index in this month over the last 4 decades.

On a seasonal scale, negative trends were found in spring, summer and winter. Decreases in precipitation in spring have also been found by authors such as Trigo and DaCamara (2000), Hurrell et al. (1995) and Paredes et al. (2006). During the summer months, negative trends in precipitation have already been described by Hurrell et al. (1995) and by the IPCC (2007). In contrast, a slightly positive, but non-significant, trend appears in autumn. Positive trends in autumn precipitation in the Duero Basin have been found by Ceballos et al. (2004).

The most prominent change in recent years is the decrease in winter precipitation (December, January, February and March). The decrease observed in recent years in the frequency of these three weather types as a result of the increase of the NAO index during these four months results in a sharp decrease in winter precipitation (Figure 7). This decline is significant, according to the Mann-Kendall test, and reflects the fact that since 1948 winter precipitation has decreased by an average of $1.4 \mathrm{~mm}$ per year.

To study the changes in precipitation behaviour in the whole period and compare it with the NAO index, a nonlinear model was checked. An order- 2 model offers a better fit than a linear model, and provides a statistically significant convex curve. This curve reaches its maximum in 1964. After that year it goes down steadily until 2008, at an average rate of $1.8 \mathrm{~mm}$ per year (Figure 7).

This decrease in precipitation during the winter months has been confirmed by Caramelo and Manso-Orgaz (2007) for the Duero Basin, del Río et al. (2005) for Castile and León, and by López-Bustins et al. (2008) for central and western zones of the Iberian Peninsula. Rodrigo and Trigo (2007) and López-Bustins et al. (2008) confirm the link between the decrease in winter precipitation in the Iberian Peninsula and changes in atmospheric circulation.

4.5. Relationship between NAO, weather types and winter precipitation

Prior to the selection of variables for the logistic regression model, a comprehensive correlation study is conducted between the December and March NAO index and rainiest weather types. The NAO index was chosen as it is the mode that best defines the variability of atmospheric circulation in the Atlantic zone of the Northern Hemisphere (Rodó et al., 1997; Trigo and Palutikof, 2001).

In the period between December and March, a considerable increase may be seen in the trend of the NAO index. The linear trend model shows that this increase occurs with a significant correlation coefficient for the months between December and March from 1948 to 2008. The Mann-Kendal test for this series illustrates that the trend began around 1978.

In contrast, a nonlinear model of the trend (in this case a third-order polynomial model) reveals that the NAO behaves in a peculiar way: it decreases from 1948 until reaching a minimum around 1962; then it increases and reaches the maximum around 1994, after which it once again decreases (Figure 8). Here we should note 


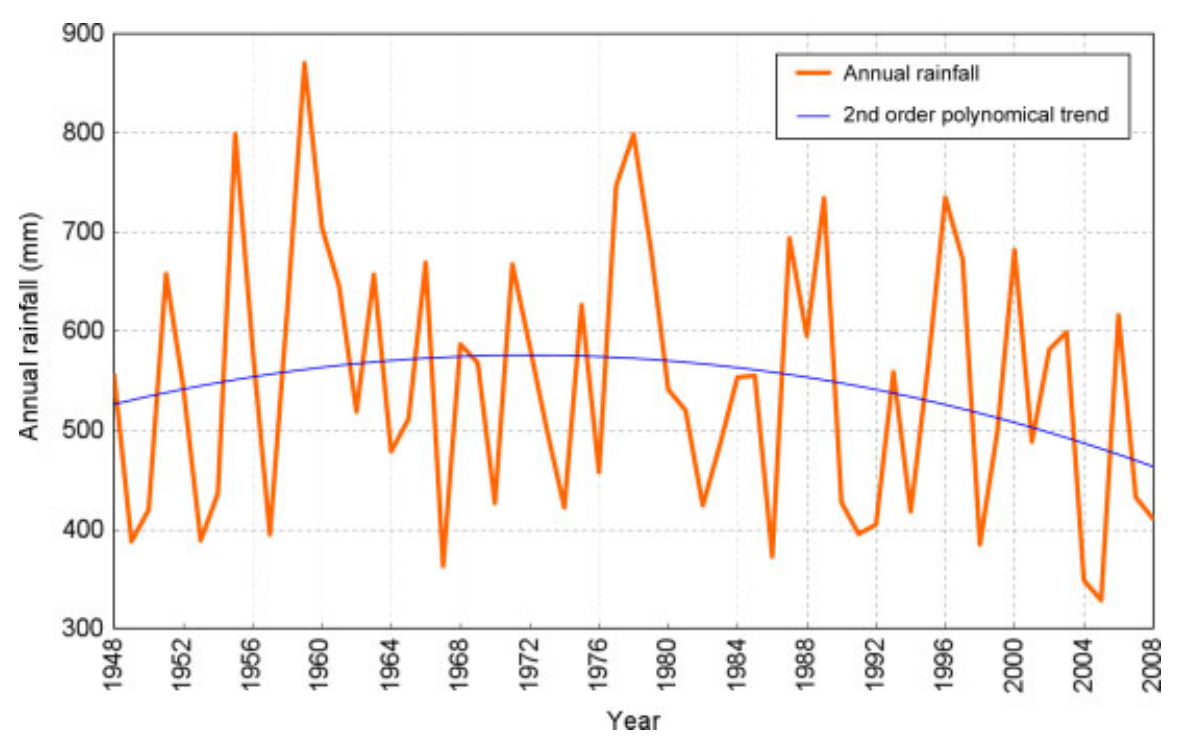

Figure 5. Evolution of annual precipitation between 1948 and 2008. This figure is available in colour online at wileyonlinelibrary.com/journal/joc

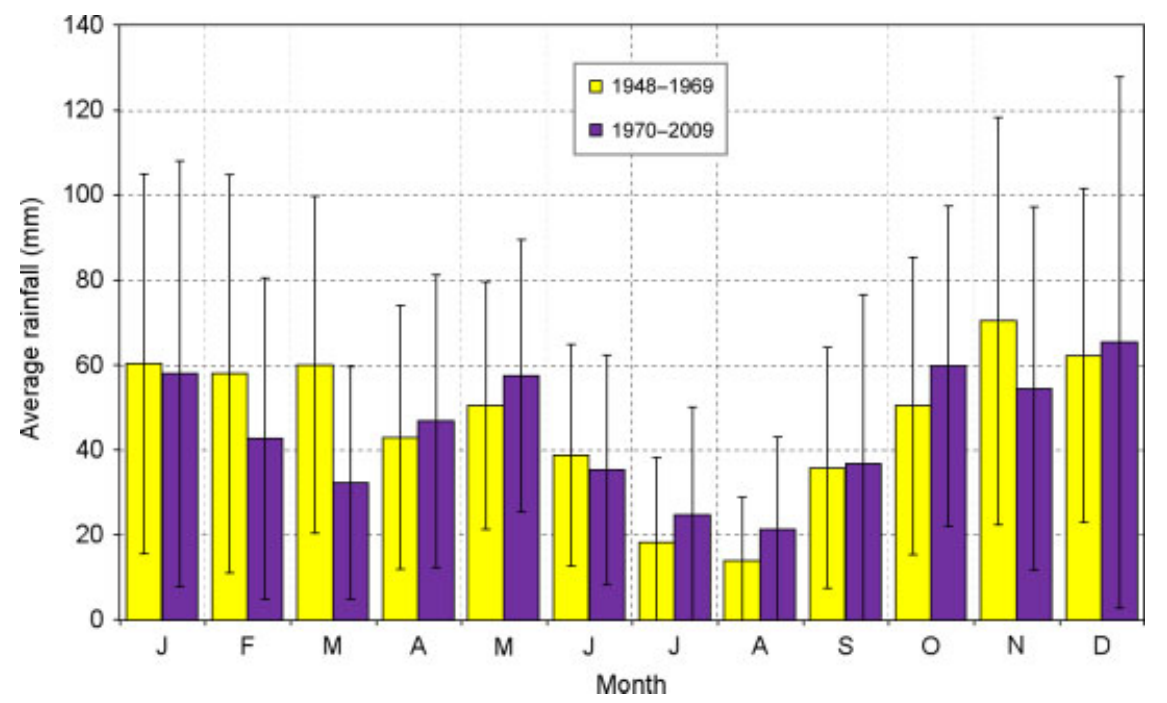

Figure 6. Monthly distribution of precipitation in the periods 1948-1969 and 1970-2008. Error bars indicate the standard deviation. This figure is available in colour online at wileyonlinelibrary.com/journal/joc

that the maximum winter precipitation is around 1964 (Figure 7), slightly later than the minimum in the NAO index. Hurrell and van Loon (1997) detected a sharper increase in the positive values of the winter NAO index from the 1980s onwards.

The increase of the NAO index in the last few decades has resulted in a decrease in the activity of the winter low-pressure systems that affect Western Europe, as observed by Trigo (2006). The main consequence associated with the increase in the NAO index during the months from December to March is the decrease in winter precipitation, shown in Figure 7.

As may be seen in Figure 8, there is a significant negative correlation $(r=-0.6)$ between the precipitation and the average NAO index in these 4 months in the winters of 1948 and 2008. In order to see the close relationship between these two variables more clearly, Figure 8 shows the standardized value of the NAO index with its sign reversed. It also shows the standardized data for the precipitation volume recorded in León. In order to obtain the standardized value, the average value for the whole period has been subtracted from the value for each winter, then dividing this result by the standard deviation.

The most spectacular result found is shown in Figure 9. This is an extremely strong correlation $(r=0.8)$ between the winter frequency of the 3 rainiest weather types ('cyclonic', 'westerly' and 'southwesterly') and the precipitation accumulated from December to March in the period 1948-2008. As in Figure 8, the standardized data are shown for the precipitation volume and the frequency of the three weather types in the months from December to March.

The two results confirm the close relationship existing between the winter precipitation recorded at the city of León, the NAO index and the rainiest weather types. 


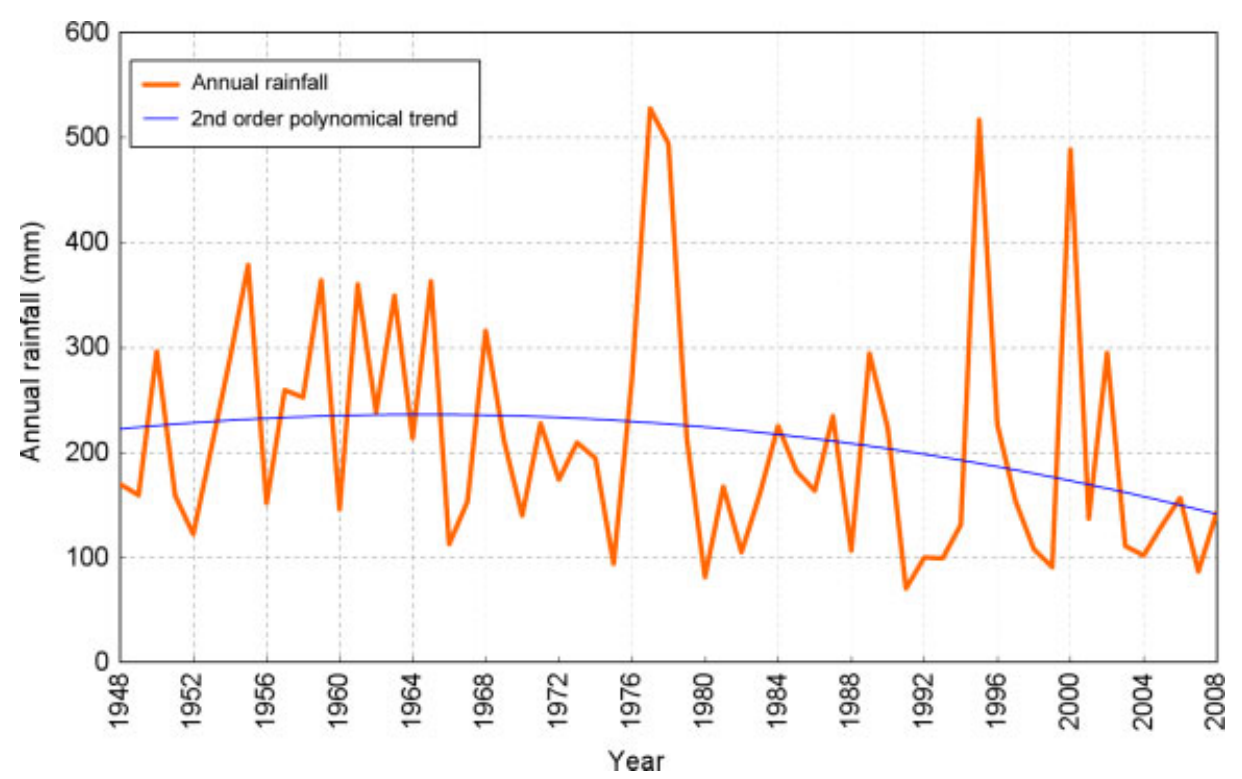

Figure 7. Evolution of precipitation between December and March in León. (1948-2008). This figure is available in colour online at wileyonlinelibrary.com/journal/joc

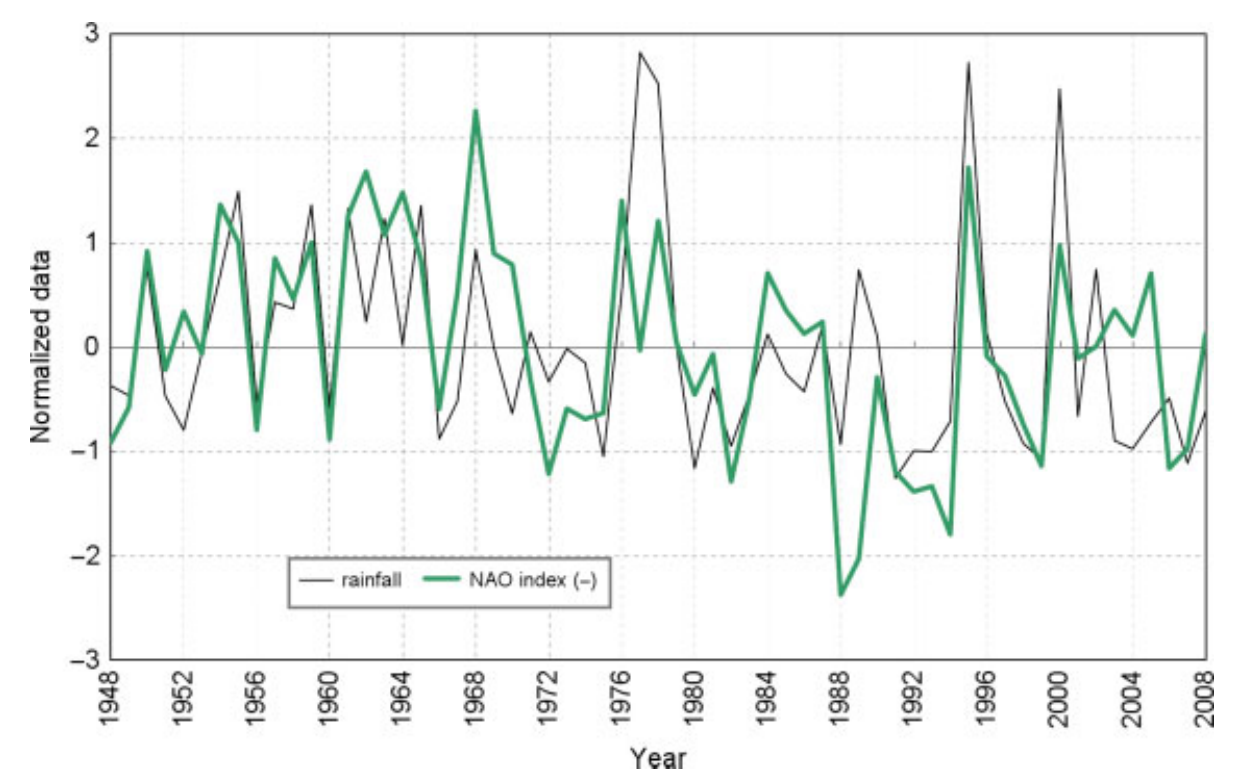

Figure 8. Relationship between the NAO index (with its sign changed) and precipitation (December-March, 1948-2008). The data have been standardized. This figure is available in colour online at wileyonlinelibrary.com/journal/joc

The results also validate the importance of the 'cyclonic' (C), 'westerly' (W) and 'southwesterly' (SW) weather types when studying the climate of León, as most of the annual precipitation in the city, especially in the winter months, appears on days with one of these three synoptic situations. These results coincide with those obtained by Lorenzo et al. (2008), who conclude that the 'cyclonic', 'western' and 'south-western' weather types (equivalent to the three described in our study), are responsible for most of the rainfall recorded throughout the year in Galicia, Spain.

In terms of weather forecasting, we can say that if we were able to forecast the value of the NAO index for a winter some months in advance, then we would be able to obtain an accurate estimate of the amount of precipitation that would be recorded in that winter. The high correlation coefficients between the NAO index, the frequency of the three rainiest weather types and winter precipitation suggests an interesting way of forecasting rainfall, if it were possible to estimate the evolution of the weather types or, as mentioned above, the NAO index. However, the medium-term forecasting of weather types involves considerable problems, so the predictive capacity described would be necessarily limited. There is always the possibility of finding a way of forecasting the NAO index using other intermediate variables, such as the sea surface temperature. Several authors have already published studies on this relationship (Zorita et al., 1992; 


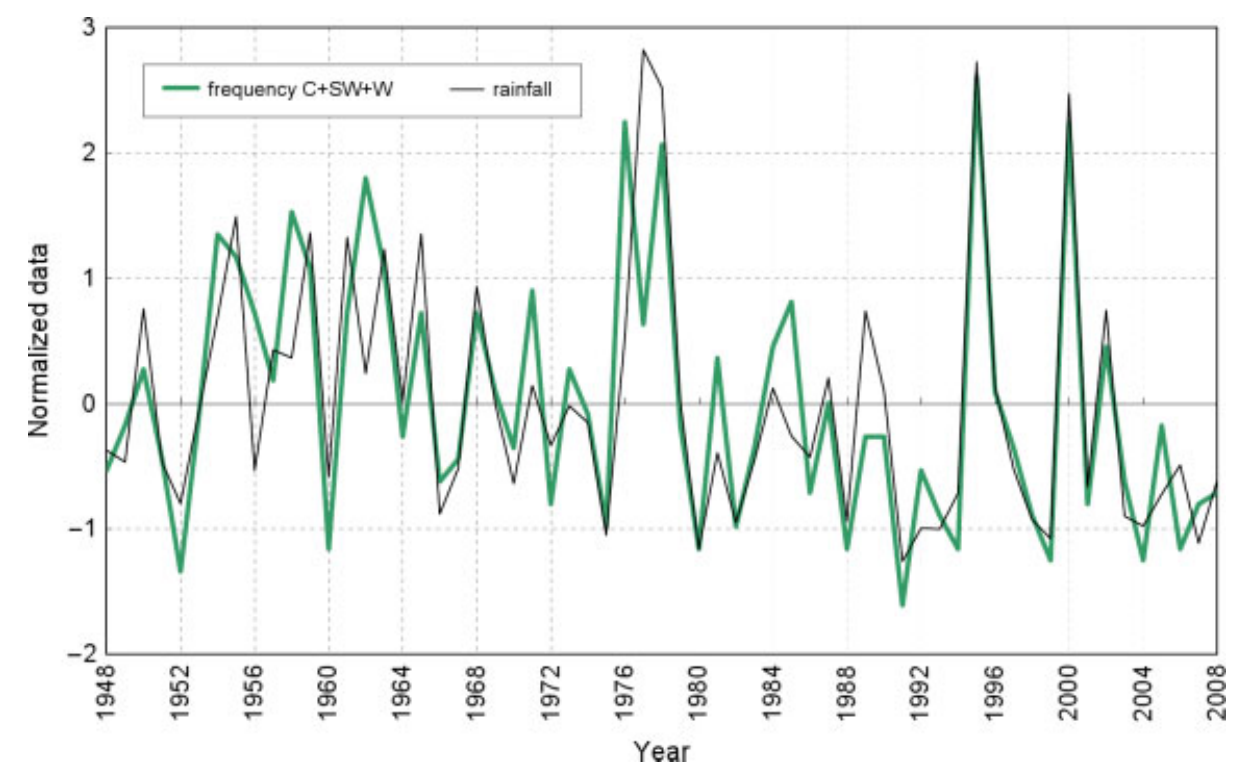

Figure 9. Relationship between the frequency of the weather types C, SW and W and precipitation between December and March. The data have been standardized. This figure is available in colour online at wileyonlinelibrary.com/journal/joc

Czaja and Frankignoul, 2001; Bojariu and Gimeno, 2003; Gámiz-Fortis et al., 2004; Losada et al., 2007). In any case, this question will be the subject of future research.

\subsection{Logistic regression model}

The method is presented as an improvement with respect to a direct downscaling from the NAO Index. The binary logistic regression model described in the last part of the Methodology section was applied. The parameters used to obtain the classification in weather types (i.e. $S F, W F, Z S, Z W, F)$ and the NAO index were used to obtain an estimate of daily precipitation in León. The dependent variable is the presence or absence of precipitation, which by being categorical can only have two values: 1 or 0 . A further series of tests were carried out using a precipitation volume of more than $0.5,1$ or $2 \mathrm{~mm}$ as the categorical variable, although worse results were obtained.

Firstly, all the days between January 1994 and March 2009 were analysed (a sample of 5569 days). The values of $\alpha$ and $\beta_{i}$ in Equation (3) were computed, and the corresponding logistic function was constructed. If the value of the logistic function $f(z)$ for a given day was higher than 0.5 , the model estimated that rainfall was recorded on that day. The goodness of the fit is not excellent: the results obtained show values for TSS, HSS and KSS lower than 0.6.

The same study was carried out again, restricting the sample to the months of December, January, February and March (a sample of 1909 days). The logistic function determines whether the model estimates that rainfall has been recorded or not on a given day.

The logistic function can take into account the presence of rain in León for specific values of $z$. What value of $z$ would best serve as the threshold for precipitation risk? Figure 10 shows the behaviour of the logistic function more clearly. It shows the observed frequency, in number of days, for each range of values of $z$, grouped in intervals of 0.2 , distinguishing between days with rain and days without rain. In this figure, we may see how around a certain value of $z$ (approximately between -0.4 and -0.5 ), the frequency of days with rain becomes higher than the frequency of days without rain. In fact, the aim is not to find a coincidence in the frequencies, but rather that the number of days with rain to the left of the threshold value of $z$ and the number of days without rain to the right of this threshold (which are the prediction values) be as small as possible.

Although the limit is frequently set at $f(z)=0.5$, in this study we have done the opposite: Huntrieser et al. (1997) used the values of TSS to determine the optimum orientation of their different storm predictors, and similarly, in this study, we have looked for the threshold value of $f(z)$ so that the skill scores have their maximum value. This value was calculated, and the result was $f(z)=0.39$. This value corresponds to a value of $z=-0.45$. The results shown in Table IV were obtained with these variables. By setting the limit of $f(z)$ as 0.39 , we obtained values for TSS $=0.64$ and HSS $=0.6$, clearly improving the values obtained with $f(z)=0.5$ $(\mathrm{TSS}=0.58 ; \mathrm{HSS}=0.56$ ).

On analysing these results, more attention has been paid to the values of TSS, as this is the most reliable index (followed by HSS), as indicated by Sohn and Park (2008) in their study on the forecast of heavy snowfall. Haklander and Van Delden (2003) found that in the case of forecasting storms in Holland, higher values are obtained using HSS than TSS. Dasgupta and De (2007) used a binary logistic regression model similar to our own in order to obtain short-term forecasts for convective rainfall. Using the method of backward selection and forward selection, the method provides better results when the probability of the threshold is reduced to 0.35 , instead of the usual figure of 0.5 . This result is similar to 


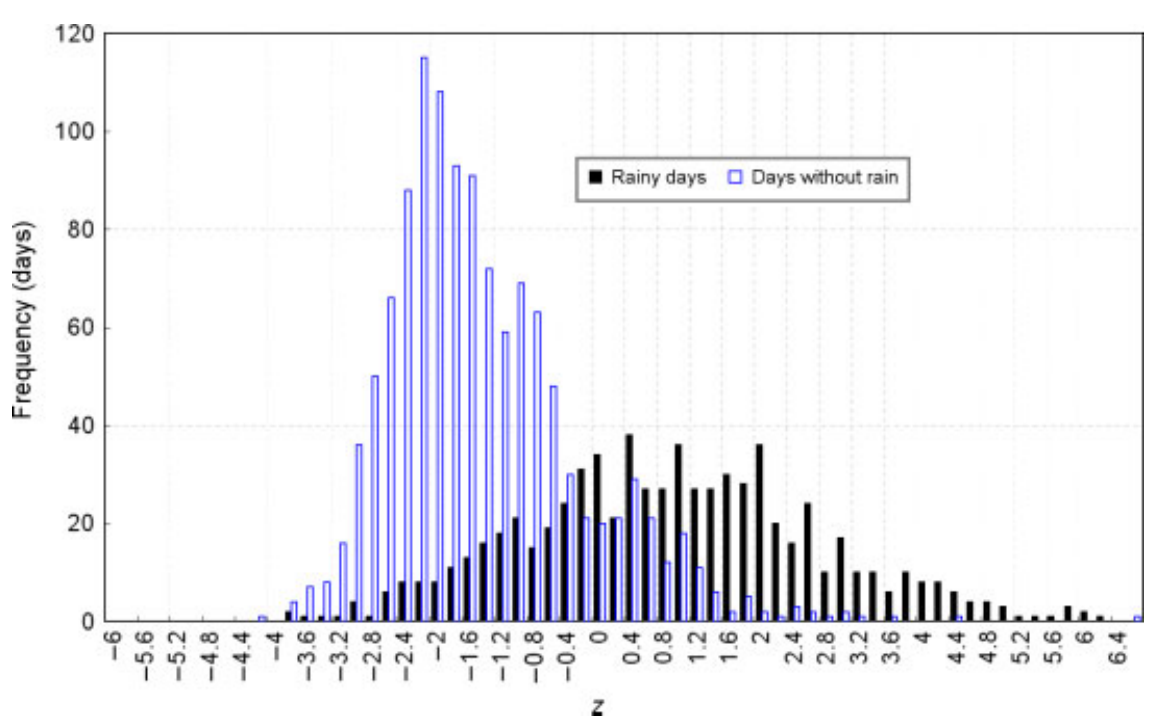

Figure 10. Frequency of the different values of $z$ grouped in intervals of 0.2, between December and March in the period between January 1994 and March 2009. This figure is available in colour online at wileyonlinelibrary.com/journal/joc

Table IV. Results obtained from the logistic regression model, with a threshold of $F(z)>0.39$ to consider a forecast for rainfall.

\begin{tabular}{llcr}
\hline & \multicolumn{2}{c}{ PREDICTED } \\
\cline { 3 - 4 } & & $F(z)>0.39$ & $F(z)<0.39$ \\
\cline { 3 - 4 } Observed & YES & 529 & NO \\
\hline & NO & 186 & 175 \\
& TSS & 0.64 & 1019 \\
\hline & HSS & 0.60 & \\
KSS & 0.59 & \\
FAR & 0.26 & \\
\hline & FOM & 0.25 & \\
\hline
\end{tabular}

that obtained in our study, in which we set the threshold at 0.39 .

Finally, do the values of the skill scores from our study represent a good result or not? It is difficult to establish comparisons with other models, especially when they involve different aspects: they either use other variables as predictors, or try to predict phenomena that are registered with different frequencies. This study cannot be compared with the usual forecasting models included in the literature on phenomena with more defined characteristics, such as those associated with strong convective activity (storms, hailstorms, etc.). We may mention the study by Zhang and Casey (2000) on the categorical forecasting of winter precipitation, who obtained TSS values between 0.1 and 0.15 , with a $11.1 \%$ probability departure.

Summing up, the authors consider that the best result of this paper is the design of a binary downscaling model for NAO and weather types in relation with precipitation. The next task will be to enlarge the study zone to a sufficiently homogeneous area, and even attempt to set up a forecast model for hydrological applications.

\section{Conclusions}

The main aim of this article was to obtain the daily classification of weather types for the city of León from January 1948 until March 2009, based on the classification of weather types developed by Lamb (1972) and improved and adapted for Iberia by Trigo and DaCamara (2000). A secondary aim was the design of a binary downscaling model for precipitation occurrence. After observing the trends in the frequency of the different weather types, the analysis focused on identifying the relationship between the increase observed in the NAO index and the decrease in precipitation in the study zone over the last few decades. The study focused on the winter months (December-March), since the influence of the $\mathrm{NAO}$ index on precipitation is stronger.

The most significant results obtained in this study are the following:

- The 'anticyclonic' weather type (A) has a clearly prevailing influence on the climate in León, with an average frequency between 1948 and 2008 of 81.4 days per year $(22.3 \%$ of the total).

- The increase in the NAO index over the past few decades is linked to the winter frequency of the 'pure anticyclone' weather type (A), which has grown significantly between 1948 and 2008. On the other hand, the increase in NAO is related to the decrease in the frequency of other weather types - 'cyclonic' (C), 'westerly' (W) and 'southwesterly' (SW) - resulting in a decrease in winter precipitation in the city of León. This is because the positive phase of the NAO is associated with an enhanced Azores anticyclone, preventing the entry of storms from the Atlantic Ocean. 
- On the basis of data from January 1994 to December 2008, just three weather types (C, SW and W) account for $55.4 \%$ of the annual precipitation. In this same period, there are five weather types with a percentage of days with rainfall higher than $70 \%(\mathrm{SW}, \mathrm{W}, \mathrm{CW}$, CSW and CNW).

- A linear analysis of the evolution of precipitation from 1948 until 2008 shows a non-significant downward trend in annual precipitation, with an average decrease of $1.1 \mathrm{~mm} / \mathrm{year}$ if we consider the whole period. An order- 2 model revealed that the annual precipitation reached its maximum in 1969, after which there is a continuous decrease by approximately $2.4 \mathrm{~mm}$ per year.

- Comparing the periods 1948-1969 and 1970-2008, we see important decreases in precipitation in the months of February, March and November. On the other hand, only slight increases have been found in the months of May, July, August and October. The decrease in the month of March is the most dramatic one, plunging from an average of $60 \mathrm{~mm}$ in the period 1948-1969, to just $33 \mathrm{~mm}$ between 1970 and 2008.

- Focusing on the winter months (from December to March), a statistically significant increase has been found in the NAO index $(r=0.3)$. Owing to the high negative correlation between the NAO index and precipitation during the winter period $(r=-0.6)$, there is a major decrease in precipitation $(r=-0.2)$.

- We found the most striking result on identifying the relationship between the frequency of the 3 rainiest weather types and the precipitation between December and March (1948-2008). The resulting correlation coefficient is 0.8 .

- Using the logistic regression model for the daily occurrence of precipitation, acceptable results were obtained $(\mathrm{TSS}=0.64)$. These results are particularly noteworthy, as only sea level pressure data were used for this model.

In the light of these results, we conclude that the increase of the NAO index observed in the past few decades, which is more acute between December and March, causes a decrease in the frequency of the three weather types responsible for most of the precipitation. As a result, there is a statistically significant decrease in winter precipitation. This proves that the NAO is the phenomenon that controls winter precipitation in the west of the Iberian Peninsula on a large scale, as suggested by Hurrel and van Loon (1997).

The decrease of cyclonic activity over the past few decades in Western Europe (Trigo, 2006), and the increasing frequency of high pressures in atmospheric circulation patterns (Stefanicki et al., 1998) may explain the decrease in winter precipitation in the Iberian Peninsula.

This paper has shown that by using exclusively pressure data to study precipitation, acceptable results are obtained for daily downscaling, although these models are more precise if they are based on a monthly basis.

\section{Acknowledgements}

This study was partially supported by the Regional Government of Castile and León (Grants LE014A07 and LE039A10-2), and by the Spanish Ministry of Education (Grants TEC2007-63216 and TEC2010-19241-C02-01).

\section{References}

Andrés M, Tomás C, de Pablo F. 2000. Spatial patterns of the daily non-convective rainfall in Castilla y León (Spain). International Journal of Climatology 20: 1207-1224.

Angus PJ, Rasmussen S, Seiter K. 1988. Short-term prediction of thunderstorm probability and intensity by screening observational and derived predictors. $15^{\text {th }}$ Conference on Severe Local Storms. AMS, Baltimore (1988). 368-371.

Billet J, Delisi M, Smith B, Gates C. 1997. Use of regression techniques to predict hail size and the probability of large hail. Weather and Forecasting 12: 154-164.

Bojariu R, Gimeno L. 2003. Predictability and numerical modelling of the North Atlantic Oscillation. Earth-Science Reviews 63: 145-168, DOI: $10.1016 / \mathrm{s} 0012-8252(03) 00036-9$.

Caramelo L, Manso-Orgaz MD. 2007. A study of precipitation variability in the Duero Basin (Iberian Peninsula). International Journal of Climatology 27: 327-339, DOI: 10.1002/joc.1403.

Castro A, Vidal MI, Calvo AI, Fernández-Raga M, Fraile R. 2011. May the NAO index be used to forecast rain in Spain? Atmósfera 24: $251-265$.

Ceballos A, Martínez-Fernández J, Luengo-Ugidos MA. 2004. Analysis of rainfall trends and dry periods on a pluviometric gradient representative of Mediterranean climate in the Duero Basin, Spain. Journal of Arid Environments 58: 215-233, DOI: 10.1016/j.jaridenv.2003.07.002.

Corte-Real J, Qian B, Xu H. 1999. Circulation patterns, daily precipitation in Portugal and implications for climate change simulated by the second Hadley Centre GCM. Climate Dynamics 15: $921-935$.

Crosby DS, Ferraro RR, Wu H. 1995. Estimating the probability of rain in a SSM/I FOV using logistic regression. Journal of Applied Meteorology 34: 2476-2480.

Czaja A, Frankignoul C. 2002. Observed Impact of Atlantic SST Anomalies on the North Atlantic Oscillation. Journal of Climate 15: 606-623.

Dai A, Fung IY, Del Genio AD. 1997. Surface observed global land precipitation variations during 1900-88. Journal of Climate 10: 2943-2962.

Dasgupta S, De UK. 2007. Binary Logistic Regression Models for short term prediction of premonsoon convective developments over Kolkata (India). International Journal of Climatology 27: 831-836, DOI: $10.1002 /$ joc. 1449 .

del Río S, Herrero L, Fraile R, Penas A. 2011. Spatial distribution of rainfall trends in Spain (1961-2006). International Journal of Climatology 31: 656-667, DOI: 10.1002/joc.2111.

del Río S, Penas A, Fraile R. 2005. Analysis of recent climatic variations in Castile and León (Spain). Atmospheric Research 73: 69-85, DOI: 10.1016/j.atmosres.2004.06.005.

Dobryshman EM. 1972. Review of Forecasting Verification Techniques. WMO: Geneva, Technical Note No. 120, 51.

Doswell CA, Davies-Jones R, Keller DL. 1990. On summary measures of skill in rare event forecasting based on contingency tables. Weather Forecasting 5: 576-585.

Esteban-Parra MJ, Rodrigo FS, Castro-Diez Y. 1998. Spatial and temporal patterns of precipitation in Spain for the period 1880-1992. International Journal of Climatology 18: 1557-1574.

Gámiz-Fortis SR, Pozo-Vázquez D, Esteban-Parra MJ, Castro-Díez Y. 2004. Influencia de la SST atlántica sobre las precipitaciones de la Península Ibérica. Física de la Tierra 16: 149-160.

García NO, Gimeno L, De La Torre L, Nieto R, Añel JA. 2005. North Atlantic Oscillation (NAO) and precipitation in Galicia (Spain). Atmósfera 18: 25-32.

García-Herrera R, Hernández E, Paredes D, Barriopedro D, Correoso U, Prieto L. 2005. A MASCOTTE-based characterization of MCSs over Spain, 2000-2002. Atmospheric Research 73: 261-282, DOI: $10.1016 / \mathrm{j}$.atmosres.2004.11.003.

González-Rouco JF, Heyen H, Zorita E, Valero F. 2000. Agreement between Observed Rainfall Trends and Climate Change Simulations in the Southwest of Europe. Journal of Climate 13: 3057-3065. 
Goodess CM, Jones PD. 2002. Links between circulation and changes in the characteristics of Iberian rainfall. International Journal of Climatology 22: 1593-1615, DOI: 10.1002/joc.810.

Goodess CM, Palutikof JP. 1998. Development of daily rainfall scenarios for southeast Spain using a circulation-type approach to downscalling. International Journal of Climatology $\mathbf{1 8}$ $1051-1083$.

Haklander AJ, Van Delden A. 2003. Thunderstorm predictors and their forecast skill for the Netherlands. Atmospheric Research 67 273-299, DOI: 10.1016/S0169-8095(03)00056-5.

Heyen H, Zorita E, von Storch H. 1996. Statistical downscaling of monthly mean North Atlantic air pressure to sea level anomalies in the Baltic Sea. Tellus 48: 312-323.

Hiliker JL, Fritsch JM. 1999. An observations-based statistical system for warm-season hourly probabilistic forecast of low ceiling at the San Francisco International Airport. Journal of Applied Meteorology 38: $1692-1705$.

Hulme M, Sheard N. 1999. Escenarios de cambio climático para la Península Ibérica. Unidad de Investigación Climática, Reino Unido, 6.

Huntrieser H, Schiesser HH, Schmid W, Waldvogel A. 1997. Comparison of traditional and newly developed thunderstorm indices for Switzerland. Weather Forecast 12: 108-125.

Hurrell JW. 1995. Decadal trends in the North-Atlantic Oscillation - regional temperatures and precipitation. Science $\mathbf{2 6 9}$ 676-679.

Hurrell JW. 1996. Influence of variations in extratropical winter-time teleconnections on Northern Hemisfere temperatures. Geophysical Research Letters 23: 665-668.

Hurrell JW, van Loon H. 1997. Decadal variations in climate associated with the North Atlantic Oscillation. Climatic Change 36 : 301-326.

Huth R, Beck C, Philipp A, Demuzere M, Ustrnul Z, Cahynova M, Kysely J, Tveito OE. 2008. Classifications of atmospheric circulation patterns. Recent Advances and Applications. In Trends and directions in climate research. Annals of the New York Academy of Sciences, Gimeno L, GarciaHerrera R, Trigo RM (eds). 1146 105-152, DOI: 10.1196/annals.1446.019.

IPCC. 2007. Summary for Policymackers. In Climate Change 2007. The Physical Science Basis. Contribution of Working Group I to the Fourth Assessment Report of the Intergovernmental Panel on Climate Change, Solomon S, Qin D, Manning M, Chen Z, Marquis M, Averyt KB, Tignor M y Miller HL (eds), Cambridge University Press: Cambridge, UK and New York, NY.

Jacovides CP, Yonetani T. 1990. An evaluation of stability indices for thunderstorm prediction in Greater Cyprus. Weather Forecasting 5 : $559-569$

Jenkinson AF, Collison FP. 1977. An initial climatology of gales over the North sea. Synoptic Climatology Branch Memorandum No. 62 Meteorological Office: Bracknell, 18.

Jolliffe IT, Stephenson DB. 2003. Forecast verification: A practitioner's guide in Atmospheric Sciences. John Wiley \& Sons: West Sussex, 240.

Jomelli V, Delval C, Grancher D, Escande S, Brunstein D, Hetu B, Filion L, Pech P. 2007. Probabilistic analysis of recent snow avalanche activity and weather in the French Alps. Cold Regions Science and technology 47: 180-192, DOI: 10.1016/j.coldregions.2006. 08.003 .

Jones PD, Hulme M, Briffa KR. 1993. A comparison of Lamb circulation types with an objective classification scheme. International Journal of Climatology 13: 655-663.

Jones PD, Jónsson T, Wheeler D. 1997. Extension to the North Atlantic Oscillation using early instrumental pressure observations from Gibraltar and South-West Iceland. International Journal of Climatology 17: 1433-1450.

Kleinbaum DG. 1992. Logistic regression. Springer-Verlag: New York. Lamb HH. 1972. British Isles weather types and register of daily sequence of circulation patterns, 1861-1971. Geophysical Memoir 116, HMSO: London, 85.

López-Bustins JA, Martín-Vide J, Sánchez-Lorenzo A. 2008. Iberia winter rainfall trends based upon changes in teleconnection and circulation patterns. Global and Planetary Change 63: 171-176, DOI: 10.1016/j.gloplacha.2007.09.002.

Lorenzo MN, Taboada JJ. 2005. Influences of atmospheric variability on freshwater input in Galician Rias in winter. Journal of Atmosphere and Ocean Sciences 10: 377-387.

Lorenzo MN, Taboada JJ, Gimeno L. 2008. Links between circulation weather types and teleconnection patterns and their influence on precipitation patterns in Galicia (NW Spain). International Journal of Climatology 28: 1493-1505, DOI: 10.1002/joc.1646.

Losada T, Rodríguez-Fonseca B, Mechoso CR. 2007. Impacts of SST anomalies on the North Atlantic atmospheric circulation: a case study for the northern winter 1995/1996. Climate Dynamics 29: 807-819, DOI: $10.1007 / \mathrm{s} 00382-007-0261-\mathrm{x}$.

Manzato A. 2005. An Odds Ratio Parametrization for ROC Diagram and Skill Scores Indices. Weather and Forecasting 20: 918-930.

Marcos-Menéndez JL. 2001. Aplicación de modelos estadísticos de decisión dicotómica para la predicción a corto plazo de tormentas y caída de granizo. PhD thesis, Universidad de León, 159.

Martín ML, Luna MY, Morata A, Valero F. 2004. North Atlantic Teleconnection patterns of low-frequency variability and their links with springtime precipitation in the western Mediterranean. International Journal of Climatology 24: 213-230, DOI: 10.1002/joc.993.

Mossmann V. 2002. Anàlise espacial e temporal das tendências das precipitações na Espanha Peninsular. Doctoral thesis, 342.

Mossmann V, Castro A, Fraile R, Dessens J, Sánchez JL. 2004. Detection of statistically significant trends in the summer precipitation of mainland Spain. Atmospheric Research 70: 43-53, DOI: 10.1016/j.atmosres.2003.11.002.

Muñoz-Díaz D, Rodrigo FS. 2004. Impacts of the North Atlantic Oscillation on the probability of dry and wet winters in Spain. Climate Research 27: 33-43.

Muñoz-Díaz D, Rodrigo FS. 2006. Seasonal rainfall variations in Spain (1912-2000) and their links to atmospheric circulation. Atmospheric Research 81: 94-110, DOI: 10.1016/j.atmosres.2005.11.005.

Panofsky HA, Brier GW. 1958. Some Applications of Statistics to Meteorology. Pennsylvania State University Press: University Park, 224.

Paredes D, Trigo RM, García-Herrera R, Trigo IF. 2006. Understanding precipitation changes in Iberia in early spring: Weather typing and storm-tracking approaches. Journal of Hydrometeorology 7: $101-113$.

Pozo-Vázquez D, Tovar-Pescador J, Gámiz-Fortis S, Esteban-Parra MJ, Castro-Díez Y. 2004. Influencia de la NAO en la variabilidad de la radiación solar en la región del Atlántico Norte. XXVIII Jornadas de la AME. 11-13 de Febrero. Universidad de Extremadura. Badajoz. Queralt S, Hernández E, Barriopedro D, Gallego D, Ribera P, Casanova C. 2009. North Atlantic Oscillation influence and weather types associated with winter total and extreme precipitation events in Spain. Atmospheric Research 94: 675-683.

Rivas-Martínez S. 2007. Mapa de series, geoseries y geopermaseries de vegetación de España. Memoria del mapa de vegetación potencial de España. Parte 1. Itinera Geobotánica 17: 1-222.

Rodó X, Baert E, Comin FA. 1997. Variations in seasonal rainfall in Southern Europe during the present century: relationships with the North Atlantic Oscillation and the El Niño-Southern Oscillation. Climate Dynamics 13: 275-284.

Rodrigo FS, Trigo RM. 2007. Trends in daily rainfall in the Iberian Peninsula from 1951 to 2002. International Journal of Climatology 27: 513-529, DOI: 10.1002/joc. 1409.

Rodríguez-Puebla C, Encinas AH, Nieto S, Garmendia J. 1998. Spatial and Temporal patterns of annual precipitation variability over the Iberian Peninsula. International Journal of Climatology 18: 299-316.

Rodríguez-Puebla C, Encinas AH, Sáenz J. 2001. Winter precipitation over the Iberian Peninsula and its relationship to circulation indices. Hydrology and Earth System Sciences 5: 233-244.

Sáenz J, Zubillaga J, Rodríguez-Puebla C. 2001. Interannual variability of winter precipitation in northern Iberian Peninsula. International Journal of Climatology 21: 1503-1513.

Sánchez JL, Fraile R, de la Fuente MT, Marcos JL. 1998. Discriminant Analysis Applied to the Forecasting of Thunderstorms. Meteorology and Atmospheric Physics 68: 187-195.

Serrano A, García JA, Mateos VL, Cancillo ML, Garrido J. 1999. Monthly modes of variation of precipitation over the Iberian Peninsula. Journal of Climate 12: 2894-2919.

Sneyers R. 1990. On the statistical analysis of series of observations. WMO (no. 415): Geneva, 192

Sohn KT, Park SM. 2008. Guidance on the Choice of Threshold for Binary Forecast Modeling. Advances in Atmospheric Sciences 25 : 83-88, DOI: $10.1007 / \mathrm{s} 00376-008-0083-8$.

Spellman G. 2000. The application of an objective weather-typing system to the Iberian peninsula. Weather 55: 375-385.

Stefanicki G, Talkner P, Webwe RO. 1998. Frequency changes of weather types in the Alpine region since 1945. Theorical and Applied Climatology 60: 47-61. 
Tomás C, Pablo F, Soriano LR. 2004. Circulation weather types and cloud-to-ground flash density over Iberian Peninsula. International Journal of Climatology 24: 109-123, DOI: 10.1002/joc.917.

Trigo IF. 2006. Climatology and interannual variability of storm-tracks in the Euro-Atlantic sector: a comparison between ERA-40 and NCEP/NCAR reanalyses. Climate Dynamics 26: 127-143, DOI: 10.1007/s00382-005-0065-9.

Trigo RM, DaCamara CC. 2000. Circulation weather types and their influence on the precipitation regime in Portugal. International Journal of Climatology 20: 1559-1581.

Trigo RM, Palutikof JP. 2001. Precipitation scenarios over Iberia: a comparison between direct GCM output and different downscalling techniques. Journal of Climate 14: 4422-4446.

Trigo RM, Pozo-Vázquez D, Osborn TJ, Castro-Díez I, GámizFortis S, Esteban-Parra MJ. 2004. North Atlantic Oscillation influence on precipitation, river flow and water resources in the Iberian Peninsula. International Journal of Climatology 24: 925-944, DOI: 10.1002/joc.1048.

Van Loon H, Rogers JC. 1978. The seesaw in winter temperatures between Greenland and northern Europe: Part I. General description. Monthly Weather Review 106: 296-310.

Wilks DS. 1995. Statistical Methods in Atmospheric Siences. Academic Press: San Diego, 467.

Zhang H, Casey T. 2000. Verification of Categorical Probability Forecast. Weather and Forecasting 15: 80-89.

Zorita E, Kharin V, von Storch H. 1992. The atmospheric circulation and sea-surface temperature in the north-atlantic area in winter - Their interaction and relevance for Iberian precipitation. Journal of Climate 5: 1097-1108.

Zorita E, von Storch H. 1997. A survey of statistical downscalling techniques. GKSS 97/E/20 42. 